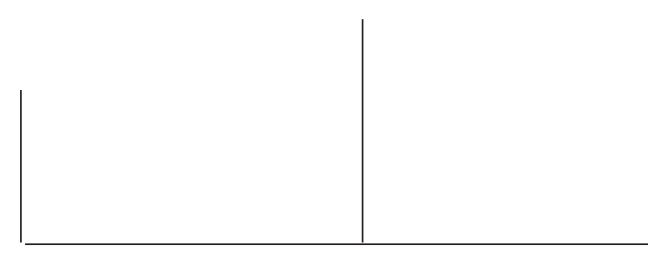

Rev. Latinoam. Psicopat. Fund., IX, 3, 508-524

\title{
O dispositivo "técnicos de referência" nos equipamentos substitutivos em saúde mental e o uso da psicanálise winnicottiana
}

\author{
Juarez Pereira Furtado e Lílian Miranda
}

\begin{abstract}
A despeito da ampla utilização do dispositivo "técnicos de referência" como forma de organizar a atenção nos Caps e outros equipamentos da reforma psiquiátrica, permanecem ainda restritos os debates e análises de suas limitações e potencialidades. Discutiremos aqui caminhos para que a organização de serviços com base em técnicos de referência não seja capturada pela administração burocrática, perdendo sua potência transformadora. Baseando-nos na clínica proposta por Winnicott, discutiremos também os problemas decorrentes da noção de "vínculo" - inerente ao dispositivo em questão - quando transposto para os serviços substitutivos de saúde mental.

Palavras-chave: Reforma psiquiátrica, centros de atenção psicossocial (CAPS), instituição pública, serviços de saúde mental
\end{abstract}




\section{O dispositivo "técnicos de referência" nos equipamentos substitutivos em saúde mental e o uso da psicanálise winnicottiana}

No início da década de 1990, baseando-se em observações sistemáticas do cotidiano de uma grande instituição asilar americana, Goffman (1992) sistematizou dados e questões próprias das formas de trabalho manicomial. Mostrou que o hospital psiquiátrico apresenta como característica central em sua condição de instituição total o atendimento das muitas necessidades humanas de maneira burocrática, realizado simultaneamente para grandes grupos de pessoas, o que tende a apagar quaisquer singularidades, no que diz respeito aos usuários e aos trabalhadores.

Considerando críticas como essa, os esforços de qualificação da assistência em saúde mental e de superação das limitações do modelo centrado no hospital direcionam-se rumo à construção de dispositivos voltados justamente para a provisão de um atendimento particularizado e flexível à polissêmica e polifônica demanda que emerge de cada caso de transtorno mental. Tais esforços ligam-se à necessidade de uma efetiva desconstrução da cultura manicomial, o que implica, necessariamente, o enfrentamento de sua essência, calcada na rígida padronização de seus procedimentos e na coletivização de suas abordagens.

Vários arranjos e dispositivos institucionais como gestão colegiada, equipes ou técnicos de referência, apoio matricial, assembléias e supervisão clínico-institucional (Onocko Campos, 2003), vêm tentar garantir aos novos equipamentos efetiva ruptura com o paradigma anterior, evitando que se tornem simplesmente serviços novos (Braga Campos, 2000; Nicácio, 2002; Amarante \& Torres, 2001). Trata-se de esforços cuja intenção é garantir conteúdos alinhados aos princípios éticos da Reforma Psiquiátrica para as novas formas de assistência representadas pelos Centros de Atenção Psicossocial (CAPS), Oficinas de Trabalho, Centros de Convivência e outros equipamentos substitutivos em saúde mental. 


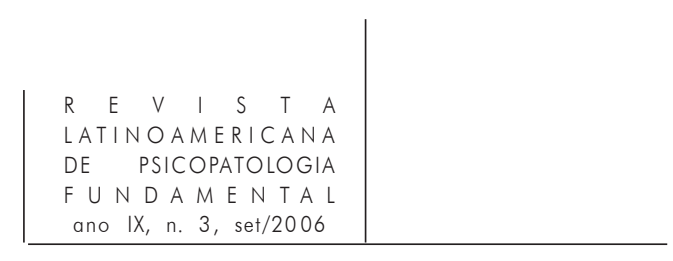

Dentre esses arranjos, consideramos o dispositivo "técnicos de referência" (Campos, 1997) especialmente importante na medida em que provê contornos ao encontro entre o trabalhador de saúde mental e o usuário do serviço. Ou seja, um dispositivo localizado na interface entre as ofertas dos equipamentos substitutivos e as demandas e necessidades apresentadas pelos usuários, marcado inevitável e necessariamente pela intersubjetividade.

A despeito, porém, da ampla utilização de técnicos de referência como forma de organizar a atenção nos equipamentos substitutivos, nossas inserções junto a serviços e políticas de saúde mental têm nos permitido identificar restritas oportunidades em que esse dispositivo é analisado e debatido. Ainda que existam muitas apropriações pertinentes, percebemos nele também utilizações burocratizadas e alienadas, desvinculadas dos condicionantes da relação entre o profissional e o paciente ou entre o profissional e seu contexto de trabalho.

Desse modo, interessa-nos analisar como a organização de serviços estruturada a partir do trabalho dos profissionais de referência pode garantir, tanto aos pacientes quanto aos trabalhadores, a capacidade de "fazer ver e falar", possibilitando, com isso, a construção de condições de expressão e de visibilidade, conforme Deleuze (1990) sugere em relação aos dispositivos. ${ }^{1}$ Portanto, gostaríamos de explorar as potencialidades e limitações do dispositivo "técnico(s) de referência”, propondo alguns possíveis caminhos para que o mesmo não seja capturado pela administração burocrática dos serviços. Utilizaremos algumas das idéias acerca da psicose, propostas pelo psicanalista Donald Winnicott, como referencial teórico para nossas reflexões acerca da relação transferencial construída entre o paciente e o profissional de referência.

\section{O técnico de referência como dispositivo}

O dispositivo técnico de referência baseia-se na idéia de que um ou mais profissionais aproximem-se de maneira especial de certo número de pacientes e passem a assisti-los de modo singular, elaborando e acompanhando junto de cada um deles um projeto terapêutico individual (Miranda, 2005).

Propõe-se que os profissionais de referência sejam de diferentes formações e componham uma equipe de referência, que se constitui na menor unidade

1. Baseando-nos em Baremblitt (1992), entendemos que “dispositivos” constituem-se em artifícios para produzir inovações, gerando acontecimentos, concretizando virtualidades, possibilitando renovações. 
organizacional do serviço. Esta desloca o poder das profissões e corporações de especialistas, reforçando o poder de gestão da equipe interdisciplinar (Campos \& Domitti, 2005). Trata-se de uma prática que ocorre dentro do que se convencionou chamar de "Saúde Mental", entendida como resultado da confluência da Psiquiatria, das diferentes escolas da Psicanálise, da Psicologia e mais recentemente da Reabilitação Psicossocial (Anthony et al., 2002), todas articuladas a conhecimentos das Ciências Sociais, o que configura um campo de saber interdisciplinar (Giordano Jr. \& Pereira, 2000) e de práticas interprofissionais (D’Amour, 1997).

Nesse cenário, a construção do projeto terapêutico se dá, em geral, a partir de várias perspectivas e com base na interação entre o paciente e seus profissionais de referência, nas interlocuções destes últimos entre si e com outros grupos como família, instituições de saúde, setores culturais e socioeducacionais etc. É função básica deste dispositivo garantir a continuidade do tratamento, evitando-se a perda do paciente nas conhecidas e descontextualizadas teias constituídas pelos “encaminhamentos". Seu sucesso está fundamentalmente ligado à ampliação da clínica (Campos, 2003), o que significa garantir que os respectivos projetos terapêuticos considerem o seguimento dos pacientes tanto no plano subjetivo como social, familiar, laboral, dentre outros, porém sempre articulados pelos profissionais de referência (Furtado, 1991).

A ampliação da clínica, porém, não será constituída pela hipertrofia das atribuições ou onipotência de uns poucos profissionais. Uma rede de outras equipes e/ou instituições deverá ser alinhavada por meio de um projeto terapêutico. Ao contrário das práticas que se contentam em remeter um dado usuário a outro serviço ou equipe, o profissional de referência deve operar para agrupar "estrelas" - representadas pelos vários serviços e instituições possíveis de serem incluídos em um certo percurso do paciente - de forma a constituir uma "constelação" articulada e dotada de sentido para aquele caso, através de um projeto terapêutico individual (Moura, 2003).

Temos, portanto, duas forças convergentes que se somam no sentido de expandir fronteiras para a atuação dos profissionais: por um lado, a busca de respostas amplas de modo a tornarem-se condizentes e efetivas em relação à complexa demanda que se apresenta em cada caso. Por outro, a própria inserção na saúde mental que, devido ao seu caráter interdisciplinar (Almeida Filho, 1997), requer ações ao menos "enxertadas" de outros saberes. Conseqüentemente, o profissional de referência opera mais no campo de competência e responsabilidade (constituído por responsabilidades e saberes comuns ou convergentes a várias profissões ou especialidades), na fronteira de vários saberes, do que em seu núcleo de competência e responsabilidade (constituído por elementos de singularidade que 


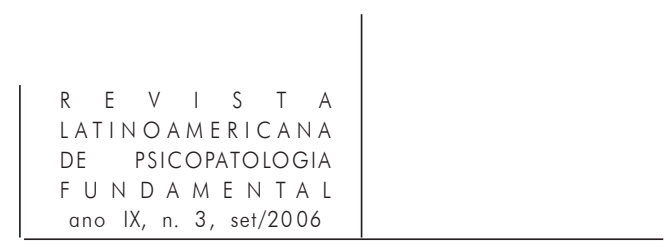

definem a identidade de cada categoria profissional ou especialista) (Campos, 1997).

A tarefa do profissional de referência, conseqüentemente, constitui-se em trabalho com e entre muitos. Por isso, o modelo de gestão e outras formas de organização do serviço deverão garantir à equipe a possibilidade de análise de seus inevitáveis conflitos, estabelecendo arranjos e dispositivos institucionais que possibilitem o convívio com a diferença - e apesar dela (Kaës, 1991). É necessária a existência de espaços de supervisão clínico-institucional, oficinas de planejamento, discussões grupais e demais iniciativas que permitam emergir e circular a palavra, considerando os conflitos e os afetos inerentes à lida intensiva com pacientes graves (Onocko Campos, 2003). Para tanto, supomos que algum grau de co-gestão deve garantir certa horizontalidade às relações hierárquicas e de poder entre os vários atores envolvidos no trabalho com situações de alta complexidade e intersubjetividade (Campos, 2000).

Como propõe Oury (1991), no tratamento da psicose o objetivo primordial é a permissão da emergência de um "si mesmo" do paciente, com toda a singularidade possível. Porém, nossa experiência clínica mostra que a qualidade da percepção de tal emergência depende de variáveis ligadas ao estado emocional do trabalhador e da equipe. Nesse sentido, poderíamos afirmar que em uma equipe na qual a criatividade e a singularidade de cada profissional é permitida e valorizada, em um contínuo processo de respeito à diversidade e fomento às potencialidades de cada um de seus membros, teremos maior chance de que seja identificado algum encanto e sentido na emergência do si mesmo de um dado paciente.

Dessa forma, modelos organizacionais e de gestão flexíveis o suficiente para permitir aos profissionais aproximarem-se tanto quanto possível de seus próprios aspectos subjetivos, peculiares e característicos - evitando conformar o coletivo de trabalhadores aos ditames dos protocolos e portarias e do que se convencionou como correto - criarão condições, por sua vez, à percepção da alteridade existente tanto entre os colegas como em relação aos pacientes.

\section{A relação entre o paciente e os seus profissionais de referência: vínculo ou transferência?}

Campos (2003) apresenta a idéia de construção de vínculo como um aspecto central do trabalho do profissional de referência. Entendendo que ela propicia o alargamento da responsabilização do profissional de saúde, ele considera vínculo como algo que indica uma relação de interdependência, co-responsabilidade e 
compromisso mútuo entre o trabalhador e o paciente, sendo isso facilitado de maneira especial pelas equipes de referência, na medida em que mediam demandas dos pacientes e possibilidades de construção compartilhada de percursos institucionais (Onocko Campos, 2003).

É inegável o alcance e potencialidade da formação de vínculo como recurso para o aumento da eficácia das ações de saúde e de introdução, nos serviços públicos, de um controle social mais efetivo, realizado pela própria clientela de usuários (Campos, 1994). No entanto, quando transposta para os cuidados aos psicóticos, a idéia de vínculo parece-nos apresentar questões importantes, o que pretendemos abordar por meio da teoria winnicottiana, pois percebemos nela contribuições fundamentais para o tratamento daqueles que sofrem de distúrbios psicóticos.

Winnicott (1954) propôs mudanças na técnica da psicanálise voltada para pacientes que sofrem de psicose, pois ao trabalhar com crianças em tenra idade e com pessoas com distúrbios psiquiátricos graves, desenvolveu sua teoria com alguns paradigmas diferentes daqueles utilizados na psicanálise freudiana (Loparic, 1997). Ele abandona termos metapsicológicos e tira o complexo de Édipo do ponto de partida da constituição da singularidade, embora o entenda como crucial para momentos em que o amadurecimento já se avançou (Dias, 2003). De modo geral, a teoria winnicottiana propõe que a interpretação e o manejo voltados a psicóticos se inscrevem na oferta de um ambiente constante e especializado, de modo que o paciente possa vivenciar uma maternagem suficientemente boa e se descolar da situação de fracasso ambiental sofrido nos períodos iniciais de seu amadurecimento (Amiralian, 2003).

Uma conseqüência imediata da adoção de concepções teóricas e técnicas de Winnicott para o tratamento de psicóticos é a necessidade de problematizar a utilização da noção de vínculo para a relação entre paciente e profissional de referência. ${ }^{2}$

A teoria winnicottiana supõe que todo ser humano possui uma tendência natural ao amadurecimento emocional e entende que esse amadurecimento se dá por meio de conquistas que se desenvolvem sucessivamente, podendo se perder e ser readquiridas ao longo da vida (Dias, 2003). Winnicott estudou de modo aprofundado uma grande série de acontecimentos anteriores ao Édipo, considerando detalhadamente a dimensão psicossomática de cada indivíduo, bem como sua relação com o ambiente em todos os processos de constituição subjetiva ou de adoecimento psíquico (Araújo, 2003). Nesse raciocínio, a origem da psicose encontra-

2. Problematizaremos as limitações da idéia de vínculo na psicose com base na teoria winnicottiana. No entanto, outros autores como Pichon-Rivière (1999) possuem posicionamentos distintos. 


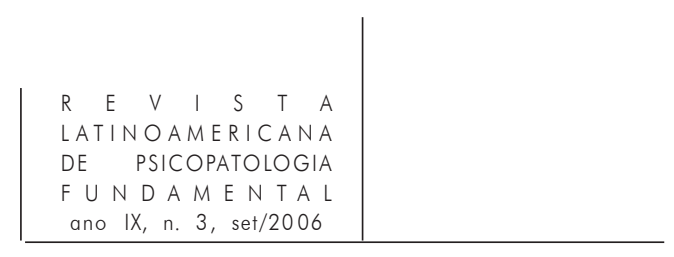

se justamente em possíveis falhas do ambiente ocorridas num momento da vida pelo autor denominado de "dependência absoluta” (Winnicott, 1963a).

Em tal estado de dependência, localizado nos primeiros dias de vida do ser humano, não há a possibilidade de se pensar na criança como sendo ela mesma uma unidade, já que ao nascer ela necessita da vivência de uma fase em que está completamente indiferenciada da mãe, de modo que não discrimina o eu do não eu (Winnicott, 1990). Assim, um bebê só consegue se sentir vivo se puder contar com a mãe como parte de si mesmo. ${ }^{3}$ Essa possibilidade de identificação com a mãe permite que ele desenvolva seu processo de percepção de si no tempo e no espaço, bem como em seu próprio corpo e na realidade, sempre com uma ilusão de onipotência que, no início da vida, é importante para afastar a ameaça da falta de controle sobre os elementos que podem invadi-lo e impedir sua sensação de estar sendo um ser em processo de integração (Araújo, 2003).

Se, por algum motivo, a mãe não prover suficientemente os cuidados vitais, deixando o filho demasiadas vezes, por períodos insuportavelmente longos, privado da saciação de algumas necessidades, ele poderá viver agonias para as quais ainda não possui condições de elaboração ou sequer de representação simbólica. Quando a repetição da vivência dessas agonias ultrapassa a capacidade maturacional do bebê, pode haver o desencadeamento da impossibilidade de confiar no mundo, pois tal repetição interrompe o processo ainda inicial de integração e impede que o bebê possa continuar sentindo sua existência (seu corpo e suas sensações) tranqüilamente.

Por ainda se encontrarem num estado em que não sentem o próprio corpo integrado e ainda não possuírem um ritmo íntimo construído (Safra, 1999), quando tomados por essas agonias, os bebês experimentam vivências a que Winnicott (1962) comparou com sensações de desintegração, de cair para sempre, de não ter conexão alguma com o corpo e de carecer de orientação. Diante dessas agonias o bebê é forçado a criar defesas, o que leva à formação dos sintomas psicóticos (ibid.). Portanto, ele "adoece e psicotiza porque não consegue mais crescer ou continuar existindo” (Araújo, 2003, p. 43).

Nessa direção, Winnicott (1963a) afirma que psicóticos, do ponto de vista emocional, possuem necessidades ligadas à reinstalação de um processo em que pudessem experimentar a sensação de continuidade da existência, desprovi-

3. Precisaremos apresentar a teorização que Winnicott constrói para os primeiros meses de vida de um bebê, porque ele supõe que a psicose se encontra em falhas localizadas nesses meses. Contudo, não estamos com isso comparando psicóticos a bebês não crescidos; apenas entendemos que adultos com sofrimentos psicóticos sofreram privações significativas no início de suas vidas, cujas conseqüências lhes acometem no presente. 
dos da urgência de se defenderem contra agonias provindas da interrupção dessa continuidade. Assim, ainda carecem de um relacionamento de identificação completa com alguém, não possuindo, por isso, um self constituído, o que pode impossibilitá-los de reconhecer uma existência própria e marcada por um si mesmo; limitação esta que inclui a restrição a vivências de relaxamento. Os psicóticos têm, nessa perspectiva, um sofrimento da ordem da impossibilidade de existir subjetivamente, tratando-se, portanto, de uma agonia que os coloca numa condição de completo desamparo em relação aos parâmetros reais da existência, como as noções socialmente compartilhadas de tempo e espaço (Safra, 1999).

Ao aceitarmos que um psicótico ainda não tem condição para reconhecer em si um modo próprio e peculiar de compreender o mundo e nele se colocar, não é possível esperarmos que ele possa genuinamente co-responsabilizar-se numa relação com o seu terapeuta ou, em nosso caso, com profissionais de referência. Não há, nesse momento, interdependência, mas dependência absoluta, ou dupla dependência. A relação neste contexto é essencial, mas não será estruturada com base na noção de vínculo, e sim de um estado em que o terapeuta se adapta às necessidades do paciente e permite que ele o utilize como objeto subjetivo (Winnicott, 1954, 1955, 1975).

A respeito da relação de dependência natural que ocorre no início da vida dos seres humanos, Winnicott (1952) afirma que o bebê cria um meio ambiente pessoal depois de experimentar uma dependência suficientemente boa do meio ambiente constituído primordialmente pela mãe. Quando o processo de dependência ocorre normalmente, o meio ambiente individual é relativamente parecido com o ambiente socialmente percebido e o indivíduo pode viver um processo de dependência relativa, alcançando, mais tarde, algum grau de independência. Porém, quando o meio ambiente social não pode se adaptar às primeiras necessidades do bebê, ele fica impedido de confiar no mundo e de viver uma ilusão de onipotência (Winnicott, 1975). Conseqüentemente, não constrói um ambiente pessoal de forma inteira e vive numa realidade agonizante e muito diversa daquela que é socialmente percebida. $\mathrm{O}$ mundo o aterroriza e se torna por demais estranho, o que o impulsiona à constituição de defesas psicóticas (Winnicott, 1952).

Winnicott (1956) chama de preocupação materna primária o estado de completa devoção ao bebê, alcançado por todas as mães que se encontram emocionalmente normais. Nesta condição a mãe é denominada de mãe ambiente e a identificação com ela permite que o bebê sinta como é ser "alguém que é", que possui identidade (Winnicott, 1975).

Tendo em vista essa conceituação, Winnicott (1954) sugere sobre o tratamento da psicose: 


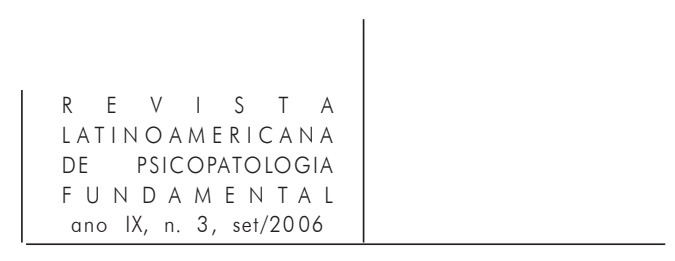

A doença psicótica se relaciona a um fracasso ambiental em estádio primitivo do desenvolvimento emocional do indivíduo. (...) O setting da análise reproduz as mais antigas técnicas de maternagem. Convida à regressão pela confiança que inspira. A regressão de um paciente é um retorno organizado à dependência inicial ou dupla dependência. O paciente e o sentting fundem-se na situação de sucesso original do narcisismo primário (...). (p. 470)

Aplicando para o espaço de trabalho do profissional de referência o raciocínio que o autor faz em relação ao setting, concluímos que a função desse profissional é primeiramente da ordem daquela exercida pela mãe suficientemente sadia que se coloca na posição de mãe ambiente. Nesse sentido, Dias (2003), ao concluir um estudo da obra winnicottiana, propõe que a mãe suficientemente boa é o paradigma do analista. Na mesma direção, embora preocupada com outro tipo de paciente, Marraccini (2005), referindo-se ao pensamento winnicottiano, propõe que há alguns pacientes que exigem um tipo especial de psicoterapia, quer seja, demandam uma provisão ambiental adaptativa, o que requer do terapeuta criatividade e tolerância a frustrações e ferimentos narcísicos.

Nesse sentido, através da relação de identificação, o profissional de referência poderia proporcionar ao paciente o que Winnicott (1975) chama de o segurar, o manejar e a apresentação de objetos. Trata-se de técnicas mais voltadas à criação de um ambiente constante e confiável - sendo esse ambiente muitas vezes a própria figura do analista - do que à interpretação do discurso do paciente. $\mathrm{O}$ objetivo, nesse tipo de tratamento, é possibilitar que o paciente possa se perceber e, para tanto, é necessário a adaptação ativa às suas necessidades básicas. A relação de identificação, porém, é, segundo Winnicott (1975), “... emocionalmente exaustiva” (p. 161), requerendo da instituição um suporte, ou, nos termos winnicottianos, um holding, análogo àquele que o pai do bebê, ou outra figura de confiança, oferece à mãe. Novamente, evidenciamos a intrínseca relação entre clínica subjetiva e organização do serviço.

Safra (1999) relata o caso de um paciente autista, cuja necessidade de isolamento e quietude fora por ele identificada e respeitada durante anos. Com isso, ele não propusera brincadeiras ou interpretações durante as sessões, mas ao cabo de muito tempo, percebendo o ritmo peculiar da respiração de seu paciente, passou a repeti-la melodicamente. Sentindo-se percebido, o paciente pôde se perceber, perceber seu ritmo psicossomático. Esse evento marcou o processo de comunicação em que o paciente podia determinar os signos que lhe eram possíveis e contar com a identificação do analista. Ao mesmo tempo, utilizando o analista como espelho (Winnicott, 1975), percebia seus signos e constituía um si mesmo. Winnicott (1955) escreve que tratara uma criança psicótica, conseguindo importante melhora de seus sofrimentos por meio de rápidos encontros semanais com ela e de sessões de orientação aos familiares. Para o autor, a mudança do 
ambiente familiar, que se adaptou às necessidades especiais da menina, puderam permitir que esta voltasse a sentir uma ilusão de onipotência e a conhecer criativamente o mundo. Com isso, pôde se perceber segura e confortável e reiniciar uma convivência menos raivosa e sofrida com a família, além de ser privada do encaminhamento a uma moradia hospitalar especializada, como era a intenção inicial da família.

Em nosso trabalho como profissional de referência, tivemos a oportunidade de procurar junto de um paciente, por vários meses, um local de moradia diferente daquele experimentado com a família. Ao mesmo tempo, conversávamos com os seus familiares de modo a ajudá-los a suportar e valorizar essa separação e a perceber no paciente uma série de potencialidades sufocadas por intensas aflições paranóides. Na busca da casa, bem como na arrumação da mesma, apenas seguíamos os passos do paciente e, ao fazê-lo, podíamos deixar mais visível para ele a sua própria forma de caminhar pela vida. Note-se que não utilizamos técnicas interpretativas ou settings tradicionais; procurávamos, no lugar disso, nos mostrar como figuras constantes e confiáveis, sem impor nossa subjetividade, mas, ao mesmo tempo, demonstrando nossa disponibilidade genuína para cuidar que o contato com o mundo (a família, os donos de pensões, os possíveis colegas de residências terapêuticas) não fosse por demais invasivo. Após um ano e meio transcorrido entre a procura de casa, a vivência da moradia e algumas mudanças de endereço, o paciente mostra-se menos paranóico, consegue cuidar de vários aspectos de sua vida pessoal e se insere em alguns circuitos sociais.

Assim, nossa experiência clínica indica que quando o processo de regressão a uma situação de dupla dependência pode se dar de modo adequado, o paciente consegue experimentar a confiança na relação criada entre ele e o profissional de referência e depois no mundo que o cerca. Essa sensação de confiança culmina numa oportunidade de integração e o paciente é capaz de envolver-se no processo de diferenciação através do qual consegue reconhecer em si um si mesmo, ainda que incipiente, e, no mundo que o cerca, alguma alteridade, ainda que relativa. Conseqüentemente, pode também começar um percurso de diferenciação de seu profissional de referência, impelindo este a exercer a função de mãe-objeto.

Tal função diz respeito à possibilidade de suportar o choque das diferenças, muitas vezes expresso através de diversas formas de agressividade, pois para Winnicott (1963b) o impulso agressivo surge primeiramente como motilidade e condição para contato com o que é externo. Quando a agressividade recebe o suporte necessário para não se transformar em destrutividade, o paciente pode perceber que há algo externo no mundo, algo que foge ao seu controle onipotente e resiste aos seus ataques.

Retomando o raciocínio que a teoria winnicottiana traça para a compreensão do processo de amadurecimento humano, é necessário notar que entre o período 


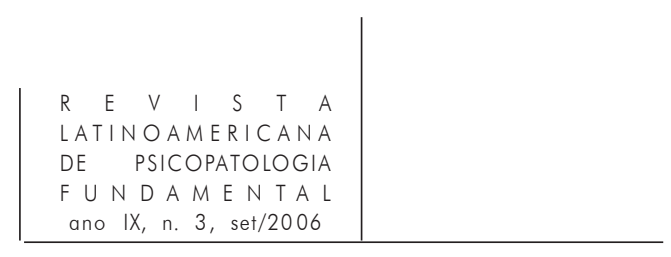

em que o bebê usa a mãe como uma mãe-objeto (Winnicott, 1952) e os primeiros momentos de vida, há um processo no qual ele adquire a transicionalidade, um espaço potencial, onde convivem aspectos referentes ao que lhe é interno e aqueles que já podem ser identificados com alguma externalidade (Winnicott, 1975). É através desse espaço que ele aprende a brincar de ser, é como se pudesse ensaiar uma existência própria, experimentando um jeito peculiar de possuir um si mesmo. A vivência suficientemente saudável desse momento permite um amadurecimento tal que as defesas psicóticas podem ser menos utilizadas em situações de agonias profundas.

Quando é permitido à criança fazer esses ensaios e retornar à condição de identificação com a mãe, como num processo de ir e vir, ela vai adquirindo a sensação de confiança num mundo que, embora externo, sempre carregará algo de pessoal. Inferimos que um processo análogo pode ocorrer no tratamento da psicose na medida em que o paciente vai obtendo condições de perceber alguma alteridade na instituição e na realidade que o cerca e pode, ao mesmo tempo, recorrer à identificação com o profissional de referência quando essa alteridade se mostra por demais ameaçadora.

No momento em que a agressividade aparece como instrumento de contato com um não eu recentemente percebido, o papel de uma terceira pessoa, muitas vezes o pai, é essencial. É uma das funções dele conter a impulsividade e mostrar tanto à criança, quanto à mãe, que a completa identificação entre eles já não é necessária. Ao mesmo tempo em que o pai impede a continuidade da fusão entre a mãe e o filho, ele também apresenta a este aspectos atraentes do mundo externo. O conhecido processo edípico então se instala (Winnicott, 1960, 1977). ${ }^{4}$

Inferimos que nas relações institucionais podem ocorrer vivências análogas, na medida em que as regras institucionais e as figuras de autoridade podem se incluir no circuito de relações do paciente. Nesse momento, a instituição se mostra como mais um entre os interlocutores que o paciente pode usar para a vivência de situações triangulares, neste caso, de modo protegido pelo raciocínio clínico da equipe que o acompanha.

Note-se que não estamos propondo que o ambiente institucional seja permissivo a quaisquer desejos dos pacientes, ou que os profissionais de referência percam sua alteridade para viverem estados de identificação patológica. Ao contrário, propomos uma especialização do ambiente, a tal ponto que haja uma

4. Não nos estenderemos no estudo do processo edípico ou da função paterna, pois para a teoria winnicottiana, como já dissemos, a psicose está ligada a uma fase anterior à edípica. Reconhecemos porém, ser essa fase essencial para quaisquer compreensões acerca da subjetividade humana. 
percepção das profundas e primitivas necessidades dos pacientes, de forma a satisfazê-las numa medida adequada. Winnicott (1956) lembra que a mãe suficientemente boa não oferece mais do que o bebê precisa, sabe que existem momentos em que a frustração é a experiência mais adequada e, quando sentida em medida suportável, pode propiciar o desenvolvimento de recursos internos.

Mais uma vez retomando o percurso do amadurecimento pessoal, deve-se notar, finalmente, que quando a criança adquire condição de brincar, podendo circular com alguma tranqüilidade entre os mundos externo e interno, ela desenvolve também a capacidade de se preocupar com o outro e de se responsabilizar por si mesma, chegando à fase que Winnicott (1963b) chama de concernimento. Essa avançadíssima conquista de amadurecimento, que ocorre em maior e menor graus, podendo perder-se e ser reconquistada no decorrer da vida de todo ser humano, oferece as condições para que os pacientes psicóticos possam, no modo peculiar de cada um deles, se responsabilizar por parte do cuidado de si e do mundo. É possível, então, vê-los respondendo por alguns de seus atos e preocupando-se, inclusive, com reinstalações de agonias insuportáveis e com o risco de atuações.

\section{Considerações finais}

Com este percurso de reflexões teóricas, há que se observar que o profissional de referência ocupa um lugar terapêutico que, não se restringindo a delimitações formais de um determinado setting, perpassa, guiado pela relação transferencial, pelas várias áreas da vida onde seu paciente encontra necessidade de algum modo de cuidado. Salientamos, porém, que esse lugar terapêutico é construído por uma fina relação baseada na transferência e na comunicação possibilitada por esta. Relação que, de acordo com a proposta de Winnicott (1954), deve ir ao encontro das necessidades do paciente, ainda que estas exijam do profissional uma extrapolação do setting e o uso intenso de seus recursos criativos. Tal extrapolação se estende para práticas que vão além do consultório e do divã, mas também podem se prolongar para fora dos grupos, oficinas terapêuticas, atendimentos familiares padronizados e todos os dispositivos alienados pela institucionalização.

Nesse modo de trabalho com a transferência, o processo de tratamento em saúde mental implica uma ampla rede de interdependência, na qual se incluem os modelos organizacionais dos serviços, as normas legais que regem o trabalho, as relações entre os colegas da equipe, com os familiares dos pacientes e os equipamentos socioculturais e de saúde. 


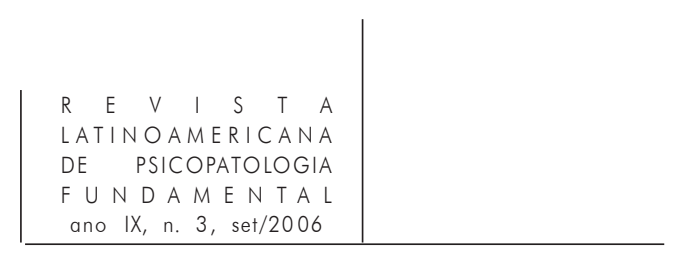

Ressaltamos que a constituição desta rede de interdependência exige uma organização institucional que promova e garanta contínuo processo de maturidade emocional dos integrantes do serviço, de tal maneira que estes possam perceber suas diferenças, potências e impotências próprias e aquelas dos colegas. De certo modo, é necessária uma madura generosidade para consigo e para com o outro.

O dispositivo "técnicos de referência” está, portanto, muito além do gerenciamento de um determinado caso. Constitui-se como um arranjo terapêutico que requer, para o seu efetivo funcionamento, um leque de outras organizações e iniciativas que apontem para a horizontalização das relações de poder, constituição de confiança entre os trabalhadores e contínua análise, avaliação e intervenção - por parte dos coletivos organizados para a produção de saúde mental - sobre os fatores intrínsecos e extrínsecos que afetam suas práticas. Toda essa gama de instrumentos, porém, deve ser, irremediavelmente, sempre guiada pelos indícios retirados da relação dos profissionais de referência com seu paciente.

Nesse caminho, esperamos ter podido contribuir com a apresentação e a análise de alguns dos aspectos que envolvem o dispositivo técnico de referência. Contudo, dada a sua importância e complexidade, salientamos que se fazem necessárias ainda mais pesquisas acerca do tema, de modo que a sua utilização na prática dos serviços de saúde possa se qualificar constantemente, bem como se calcar em bases teóricas sólidas e claras. ${ }^{5}$

\section{Referências}

Almeida Filho, N. Transdisciplinaridade e Saúde Coletiva. Ciência e saúde coletiva II, n. 1/2, 1997.

Amarante, P. \& Torres, E. H. G. A constituição de novas práticas no campo da Atenção Psicossocial: análise de dois projetos pioneiros na Reforma Psiquiátrica no Brasil. Saúde em debate, v. 25, n. 58, p. 26-34, 2001.

Amiralian, M.L.T.M. A clínica do amadurecimento e o atendimento de pessoas com deficiências. Natureza Humana. Revista internacional de filosofia e práticas psicoterápica, São Paulo, v. 5, n. 1, p. 205-19, jan.-jun./2003.

Anthony, W.; Cohen, M.; Farkas, M. e Gagne, C. Psychiatric Rehabilitation. Boston: Boston University, 2002.

5. Estamos iniciando, junto ao grupo de pesquisa Saúde Mental e Saúde Coletiva: interfaces, do Departamento de Medicina Preventiva da Unicamp, uma pesquisa de doutorado que objetiva estudar a utilização desse dispositivo junto aos CAPS da cidade de Campinas. 
Araúso, C. A. S. O autismo na teoria do amadurecimento de Winnicott. Natureza humana. Revista internacional de filosofia e práticas psicoterápicas, v. 5, n. 1, p. 39-59, 2003.

Baremblitt, G. Compêndio de Análise Institucional e outras correntes: teoria e prática. Rio de Janeiro: Rosa dos Ventos, 1992. 171 p.

Braga Campos, F. C. B. O modelo da Reforma Psiquiátrica brasileira e as modelagens de São Paulo, Campinas e Santos. 2000. Tese (doutorado em Saúde Coletiva). Universidade Estadual de Campinas.

CAmpos, G. W. S. Considerações sobre a arte e a ciência da mudança: revolução das coisas e reforma das pessoas. A casa da saúde. In: Merhy, E.; Campos, G. W. S. \& Cecílio, L. C. O. (orgs.). Inventando a mudança na saúde. São Paulo: Hucitec, 1994.

Subjetividade e administração de pessoal: considerações sobre modos de gerenciar trabalho em equipes de saúde. In: Merhy, E. \& Onocko Campos, R. (orgs.). Agir em saúde. São Paulo: Hucitec, 1997.

Um método para análise e co-gestão de coletivos: a constituição do sujeito, a produção de valor de uso e a democracia em instituições: o método da roda. São Paulo: Hucitec, 2000.

Saúde paidéia. São Paulo: Hucitec, 2003.

Campos, G. W. S. \& Domitti, A. C. Apoio matricial e equipe de referência: uma metodologia para gestão do trabalho interdisciplinar em saúde, 2005. Mimeo.

D’Amour, D. Structuration de la collaboration interprofessionelle dans les services de santé de première ligne au Québec, Montreal. 1997. Tese ( doutorado). Université de Montréal.

Deleuze, G. Que és un dispositivo? In: Michel Foucault, filósofo. Barcelona: Gedisa, 1990.

Dias, E. A teoria do amadurecimento de D. W. Winnicott. Rio de Janeiro: Imago, 2003.

Furtado, J. P. \& Onocko Campos, R. A transposição das políticas públicas de saúde mental no Brasil para a prática nos novos serviços. Revista Latinoamericana de Psicopatologia Fundamental, v. 8, n. 1, p. 109-22, jan./2005.

FurTado, J. P. Responsabilização e vínculo no tratamento de pacientes cronificados: da unidade de reabilitação de moradores ao Caps Estação. In: Harari, A. e VAlEntini, W. (orgs.). A reforma psiquiátrica no cotidiano. São Paulo: Hucitec, 1991.

Goffman, E. Manicômios, prisões e conventos. São Paulo: Perspectiva, 1992.

Giordano Jr., S. \& Pereira, L. M. F. Saúde mental. In: Schraiber, L. B.; Nemes, M. I. B. 


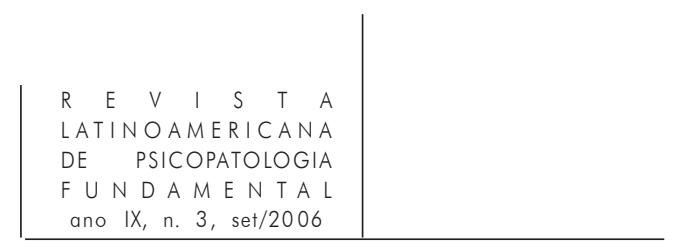

e Mendes-Gonçalves, R. B. (orgs.). Saúde do adulto: programas e ações na unidade básica. São Paulo: Hucitec, 2000.

KAËs, R. Realidade psíquica e sofrimento nas instituições. In: KaËs, R.; Bleger, J.; ENriquez, E.; Fornari, F.; Fustier, P.; Roussillon, R. \& Vidal, J. P. (orgs.). A instituição e as instituições. Trad. de Joaquim Pereira Neto. São Paulo: Casa do Psicólogo, 1991.

Loparic, Z. Winnicott e Melanie Klein: conflito de paradigmas. In: Catafesta, I.F. (org.). A clínica e a pesquisa no final do século: Winnicott e a universidade de São Paulo. São Paulo: Instituto de Psicologia da USP, 1997. p. 43-60.

Marracini, E.M. Uma vida que se esvai no Parkison. Revista Latinoamericana de Psicopatologia Fundamental, São Paulo, v. VIII, n. 1, p. 40-53, mar./2005.

MiRANDA, L. Projeto Terapêutico Individual: a necessária disponibilidade para relações humanas, 2005. Mimeo.

Moura, A.H. A psicoterapia institucional e o clube dos saberes. São Paulo: Hucitec, 2003. 190 p.

NICÁcıo, M. F. Utopia da realidade: contribuições da desinstitucionalização para a invenção de serviços de saúde mental. 2002. Tese (doutorado em Saúde Coletiva). Universidade Estadual de Campinas.

Onocko CAmpos, R. A gestão: espaço de intervenção, análise e especificidades técnicas. In: Campos, G. W. S. (org.). Saúde paidéia. São Paulo: Hucitec, 2003.

OuRY, J. Itinerários de formação. Revue Pratique, n. 1, p. 42-50, 1991.

Pichon-Rivière, E. Teoria del vínculo. Buenos Aires: Nueva Visón, 1999.

SAFrA, G. A face estética do self: teoria e clínica. 2. ed. São Paulo: Unimarco, 1999.

Toledo, M. L. A clínica do amadurecimento e o atendimento às pessoas com deficiência. Natureza humana: revista de filosofia e práticas psicoterápicas, v. 5, n. 1, p. 205-23, 2003.

Winnicott, D. W. (1952). Psicose e cuidados maternos. In: Textos selecionados: da pediatria à psicanálise. Rio de Janeiro: Francisco Alves, 1978.

(1954). Aspectos clínicos e metapsicológicos da regressão dentro do setting psicanalítico. In: Textos selecionados: da pediatria à psicanálise. Rio de Janeiro: Francisco Alves, 1978.

(1955). Variedades clínicas na transferência. In: Textos selecionados: da pediatria à psicanálise. Rio de Janeiro: Francisco Alves, 1978.

(1956). Preocupação maternal primária. In: Textos selecionados: da pediatria à psicanálise. Rio de Janeiro: Francisco Alves, 1978. 
(1960). Teoria do relacionamento paterno-infantil. In: O ambiente e os processos de maturação. Porto Alegre: Artes Médicas, 1983.

(1962). A integração do ego no desenvolvimento da criança. In: O ambiente e os processos de maturação. Porto Alegre: Artes Médicas, 1983.

(1963a). Os doentes mentais na prática clínica. In: O ambiente e os processos de maturação. Porto Alegre: Artes Médicas, 1983.

(1963b) O desenvolvimento da capacidade de se preocupar. In: O ambiente $e$ os processos de maturação. Porto Alegre: Artes Médicas, 1983.

O brincar e a realidade. Rio de Janeiro: Imago, 1975.

A criança e seu mundo. Rio de Janeiro: Zahar, 1977.

Natureza humana. Rio de Janeiro: Imago, 1990.

\section{Resumos}

A pesar de la amplia utilización del dispositivo "técnicos de referencia" como forma de organizar la atención en los CAPS y otros equipamientos de la reforma psiquiátrica, permanecen todavía restrictos los debates y el análisis de sus limitaciones y potencialidades. Discutiremos aquí caminos para que la organización de servicios con base en técnicos de referencia no sea capturada por la administración burocrática, perdiendo su potencia transformadora. Basándonos en la clínica propuesta por Winnicott, discutiremos también los problemas derivados de la noción de "vínculo" inherente al dispositivo en cuestión - cuando transpuesto para los servicios substitutivos de salud mental.

Palabras clave: Reforma psiquiátrica, centros de atención psico-social (CAPS), institución pública, servicios de salud mental

Malgré l'utilisation très répandue du dispositif du "technicien de référence" comme moyen pour organiser l'attention dans les Caps et autres équipements de réforme psychiatrique, les débats et les analyses sur leurs limitations et potentiels sont encore rares. Nous discuterons ici les chemins pour que l'organisation des services basés sur les techniciens de référence ne soit pas capturée par l'administration bureaucratique et perde, ainsi, son potentiel transformateur. En prenant comme base la clinique proposée par Winnicott, nous discuterons aussi les problèmes qui découlent de la notion du "lien" - inhérent au dispositif en question - quand il est transféré aux services substitutifs de santé mentale.

Mots clés: Réforme de psychiatrie, centres d'attention psychosociale (CAPS), établissement public, services de santé mental 


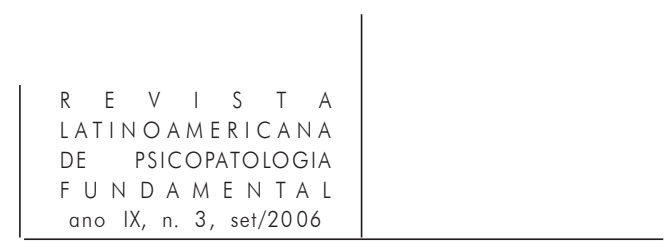

Despite the widespread use of the term "reference teams" as a way of organizing treatment in psychosocial assistance centers (known in Brazil as CAPS - Centros de Atenção Psicossocial) and other sites of psychiatric reform, debates and analysis on their weaknesses and potentialities are still limited. This article discusses possible ways of preventing bureaucratic administrative processes from reducing the potential for transformating services based on "reference teams." This paper also uses the medical treatment proposed by Winnicot and discusses problems brought up by the notion of bonds - intrinsic to the term "reference team" - when used in regard to alternative mental health services.

Key words: Psychiatric reform, psychosocial assistance centres (CAPS), public institution, mental health services 